\title{
On uniqueness of equilibria in the CAPM
}

\section{Working Paper}

Author(s):

Hens, Thorsten; Laitenberger, Jörg; Löffler, Andreas

Publication date:

2000

Permanent link:

https://doi.org/10.3929/ethz-a-004373402

Rights / license:

In Copyright - Non-Commercial Use Permitted

Originally published in:

Working paper / Institute for Empirical Research in Economics 39 


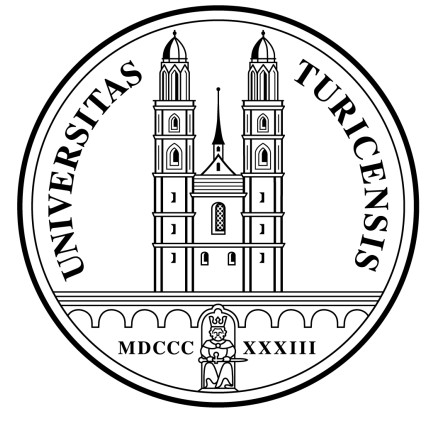

Institute for Empirical Research in Economics

University of Zurich

Working Paper Series

ISSN 1424-0459

Working Paper No. 39

\section{On Uniqueness of Equilibria in the CAPM}

(This paper replaces the paper

"Existence and Uniqueness of Equilibria in the CAPM")

Thorsten Hens, Jörg Laitenberger and Andreas Löffler

July 2000 


\title{
ON UNIQUENESS OF EQUILIBRIA IN THE CAPM
}

\author{
By Thorsten Hens, Jörg Laitenberger and Andreas Löffler*
}

July 2000

This paper replaces the paper "Existence and Uniqueness of Equilibria in the CAPM"

Institut für Empirische Wirtschaftsforschung, Universität Zürich, Switzerland; thens@iew.unizh.ch

and

Price Waterhouse Coopers Corporate Finance, Olof-Palme-Str. 35, 60439 Frankfurt/Main, Germany.

and

Fachbereich Wirtschaftswissenschaft, Freie Universität Berlin, Boltzmannstr. 20, 14195

Berlin, Germany; al@dcf-verfahren.de.

${ }^{*}$ Löffler acknowledges financial support from DAAD, Bonn. We thank Lutz Hendricks and two anonymous referees for very helpful comments. 


\begin{abstract}
In the standard CAPM with a riskless asset we give a sufficient condition for uniqueness.This condition is a joint restriction on the agents' endowments and their preferences which is compatible with non-increasing absolute risk aversion and which is in particular satisfied with constant absolute risk aversion. Moreover in the CAPM without a riskless asset we give an example for multiple equilibria even though all agents have constant absolute risk aversion.
\end{abstract}

JEL Class.: G10, C62

keywords: CAPM, uniqueness, risk aversion 


\section{INTRODUCTION}

Nowadays the classical two-period Capital Asset Pricing Model is one of the cornerstones of modern finance. Developed by Sharpe (1964), Lintner (1965), and Mossin (1966), it is widely used both by practitioners and theoreticians, since it gives us a managable and attractive way of thinking about risk and required return on a risky investment. Given this succesful theory one is forced to ask why the question of uniqueness of equilibria was not intensively investigated for a long time. It should be clear that without uniqueness the CAPM looses much of its relevance: if there are many equilibria, on which can investors base their investment decisions? And what is the "correct" risk premium for risky assets? In this paper we give a condition for uniqueness of CAPM-equilibria which is based on the risk aversion and the endowments of the investors. Our condition is compatible with non-increasing absolute risk aversion.

It was Nielsen (1988) who showed that the static CAPM equilibrium (even in a very simplified example) need not to be unique. There may be several equilibria, all with identical expected total returns, covariances, utility functions, and initial distributions of cash flows. In every CAPM equilibrium, risk is measured in the same way (via the capital market line) but the risk premium is indeterminate. And even worse as it was recently shown by Bottazzi et al. (1998), the situation described by Nielsen is by no means exceptional. For every risky market portfolio there are CAPM economies that have arbitrarily many equilibria. This result shows that one cannot expect a general theorem establishing uniqueness for a broad class of CAPM economies.

Up to now only special cases are known in which the static CAPM possesses a unique equilibrium: for example, if utility functions are quadratic or if investors have expected utility functions with constant absolute risk aversion and returns are jointly normally distributed. Nielsen (1988) considered the question of uniqueness but he did not give a result that relies on economic fundamentals, i.e. endowments or utility functions, alone. Dana (1999) seems to be the most general result on uniqueness. Unfortunately, her criterion is based on the assumption of an additively separable mean-variance utility function which is difficult to interpret economically. Furthermore, Dana assumes the mean-variance utility function to be concave. It can be shown that concavity of the mean-variance utility together with Dana (1999) assumption implies non-decreasing absolute risk aversion.

Our purpose is to give a uniqueness result that relies only on economically interpretable assumptions. We show that under non-increasing absolute risk aversion a joint restriction on utility functions and endowments implies uniqueness in the CAPM with a riskless asset. It is a common contention that non-increasing absolute risk aversion is a plausible property of utility functions of investors.For example, experiments (see Levy (1964)) as well as empirical studies (see Dalal \& Arshanapalli (1993)) have shown that constant relative risk aversion is very plausible. This gives evidence for decreasing absolute risk aversion. In particular, our condition is satisfied if all investors exhibit constant absolute risk aversion.

Merton (1973) has developed a continuous time version of the CAPM. Recently Karatzas 
et al. (1990) obtained a uniqueness result for this continuous time model which is based on the assumption of relative risk aversion being smaller than one. But this condition is not compatible with $\mu-\sigma$ utility functions as was shown by Löffler (2000). Hence, the idea of Karatzas et al. (1990) cannot be applied to the static CAPM.

Our uniqueness result relies heavily on the existence of a riskless asset. This assumption is far from being trivial. Indeed, we will show in section 4 that even in the case when all investors exhibit constant absolute risk aversion, examples of economies with multiple equilibria can be constructed for the CAPM without a riskless asset. The only condition we know which guarantees uniqueness of equilibria even for the CAPM without a riskless asset has been given in Allingham (1991). When the CAPM utility functions are derived from expected utility maximization and when asset returns are normally distributed, then agents do not only exhibit constant absolute risk aversion but represented in a mean-variance diagram indifference curves are parallel straight lines.

It should be noted why uniqueness of CAPM-equilibria cannot be derived as a corollary of the uniqueness results known in the standard general equilibrium model (cf. Arrow 83 Hahn (1971) or Mas-Colell et.al. (1995)). After all the CAPM can be seen as a general equilibrium model with two goods: mean and variance. However, in some important aspects the CAPM differs from the standard general equilibrium model. One of the 'goods', the variance, is not desired and for the other good there are no non-negativity constraints. In particular, there are no non-negativity constraints on the set of attainable payoffs. Introducing such constraints in the CAPM would rule out the important case of normally distributed returns, and moreover, would conflict with the Tobin separation property, a key property of the CAPM. Moreover, in contrast to the standard differentiable approach to general equilibrium theory $\mathrm{Mas}-\mathrm{Colell}$ (1985), indifference curves in the CAPM intersect with the boundary of the consumption set.

The paper is organized as follows. The next section presents the general CAPM in $L^{2}(\nu)$, and then derives an equivalent two commodity representation. Section 3 gives the uniqueness result for the CAPM with a riskless asset. Section 4 presents an example of a CAPMeconomy without a riskless asset that exhibits multiple equilibria even though all investors exhibit constant absolute risk aversion.

\section{THE MODEL}

The model is essentially a static two-period Capital Asset Pricing Model in a General Equilibrium framework, as it is presented in most modern Finance textbooks, see e.g. Duffie (1988) or more recently LeRoy \& Werner (2001). There are two dates $t=0,1$. At date 1 several possible states of the world $s$ can occur. The uncertainty about these states is common among all agents, and described by a probability space $(S, \mathcal{S}, \nu)$. Consumption takes place only at date 1 .

A consumption bundle $x$ is a real-valued measurable function on $(S, \mathcal{S}, \nu)$. For technical reasons, the consumption set will be restricted to the set of measurable functions with finite 
variance:

$$
L^{2}(\nu)=\left\{x \mid \mathrm{E}\left(x^{2}\right)<\infty\right\}
$$

where $\mathrm{E}(x):=\int_{S} x(s) d \nu$ is the expected value of $x . L^{2}(\nu)$ is a Hilbert-space, when endowed with the probability adjusted scalar product $x \cdot y=\mathrm{E}(x y)=\int_{S} x(s) y(s) d \nu$ and with the Norm $\|x\|=\sqrt{\mathrm{E}\left(x^{2}\right)}$. The covariance-bilinearform $\operatorname{Cov}(x, y)=\mathrm{E}(x y)-\mathrm{E}(x) \mathrm{E}(y)$ and the variance-operator $\operatorname{Var}(x)=\operatorname{Cov}(x, x)$ are defined as usual.

Endowments of the agents are vectors in $L^{2}(\nu)$. In order to shift consumption among states, the agents may trade assets at date zero, that is, before uncertainty has resolved. An asset is a contract that promises the delivery of some amount of the good in each state of the world at date one. This amount can be negative in some states, as it is for instance when the payoffs of the securities are normally distributed. It is modeled as well as a vector in $L^{2}(\nu)$. The set of existing non-redundant assets is denoted by $Y$. There can be potentially an infinite number of securities, but for notational convenience we will always use the symbol ' $\sum$ ' when summing over $Y$. In any case $Y$ is supposed to be closed. There are no short sales constraints, such that the agents may buy or sell any amount of these assets that they can afford. The set of possible trades of date-1-consumption is given by the linear combinations of securities in $Y$, thus by $\langle Y\rangle$, the space spanned by $Y$. The following portfolio $\eta$ plays a key role in the CAPM. It is the portfolio which solves the minimization problem

$$
\min \{\operatorname{Var}(z) \mid \mathrm{E}(z)=1, z \in<Y>\}>0 .
$$

This portfolio exist because $Y$ is closed. The following Lemma summarizes two properties of $\eta$ :

\section{Lemma 1}

1. The vector $\eta$ is collinear to the orthogonal projection of the riskless asset 1 onto < $Y>$, where orthogonality is meant with respect to the probability adjusted scalar product.

2. For all $y$ in $\langle Y>$ : $\operatorname{Cov}(\eta, y)=\operatorname{Var}(\eta) E(y)$

Proof. 1. Let $\hat{\eta}$ be the projection of $\mathbf{1}$ onto $\langle Y\rangle$.

$$
\begin{aligned}
\hat{\eta} & =\arg \min \left\{\|z-\mathbf{1}\|^{2} \mid z \in<Y>\right\} \\
& =\arg \min \left\{\left|\mathrm{E}\left(z^{2}\right)-2 \mathrm{E}(z)+1\right| \mid z \in<Y>\right\} \\
& =\arg \min \left\{\left|\operatorname{Var}(z)+\mathrm{E}(z)^{2}-2 \mathrm{E}(z)+1\right| \mid z \in<Y>\right\} \\
& =\arg \min \left\{\operatorname{Var}(z)+(\mathrm{E}(z)-1)^{2} \mid z \in<Y>\right\} .
\end{aligned}
$$

Since both $\operatorname{Var}(z) \geq 0$ and $(E(z)-1)^{2} \geq 0$ one can conclude

$$
\begin{aligned}
\hat{\eta} & =\arg \min \{\operatorname{Var}(z) \mid \mathrm{E}(z)=\mathrm{E}(\hat{\eta}), z \in<Y>\} \\
& =\mathrm{E}(\hat{\eta}) \eta .
\end{aligned}
$$


2. Consider the space spanned by $\eta$ and $y$. Clearly, since $y \in\langle Y\rangle$,

$$
\eta=\arg \min \{\operatorname{Var}(z) \mid \mathrm{E}(z)=1, z \in<\eta, y>\} .
$$

Any $z \in<\eta, y>$ is of the form $z=\alpha_{1} \eta+\alpha_{2} y$ with some $\alpha \in \mathbb{R}^{2}$. The above minimization can be written as a Lagrange-problem of the following form:

$$
\min \alpha^{T} \Omega \alpha, \quad \text { subject to } \alpha \bar{y}=1,
$$

where $\Omega=\left(\begin{array}{cc}\operatorname{Var}(\eta) & \operatorname{Cov}(\eta, y) \\ \operatorname{Cov}(\eta, y) & \operatorname{Var}(y)\end{array}\right)$ and $\bar{y}=\left(\begin{array}{c}1 \\ \mathrm{E}(y)\end{array}\right)$ are the variance-covariancematrix and the vector of expected returns, respectively. The solution of this problem computes as $\alpha=\lambda \Omega^{-1} \bar{y}$ with some Lagrange multiplier $\lambda>0$. Since at the minimum $z=\eta$, it must be that $\alpha_{2}=0$. But this implies

$$
-\operatorname{Cov}(\eta, y)+\operatorname{Var}(\eta) \mathrm{E}(y)=0 .
$$

A price $p$ of a payoff-stream $x$ in $\langle Y\rangle$ can be identified by virtue of the Riesz representation theorem as a vector in $\langle Y\rangle$. There are $I$ agents $i=\{1, \ldots, I\}$ described by their utility functions $u^{i}$ and their endowments $\omega^{i}$. The following assumptions are made:

The preference of every agent $i$ can be represented by a mean-variance utility function, that is $u^{i}(x)=v^{i}(\mu(x), \sigma(x))$ for all $x$ in $L^{2}(\nu)$, with $v^{i}: \mathbb{R} \times \mathbb{R}_{+} \rightarrow \mathbb{R}$ increasing in $\mu(x)=$ $E(x)$, decreasing in $\sigma(x)=\sqrt{\operatorname{Var}(x)}$, continuously differentiable and strictly quasi-concave.

The endowments are 'spanned': for all $i, \omega^{i} \in\langle Y\rangle$. Equivalently, there exist portfolios $\alpha^{i} \in \mathbb{R}^{J}$ such that $\omega^{i}=\sum_{j} \alpha_{j}^{i} y_{j}$. Furthermore, for the market portfolio $\omega=\sum_{i} \omega^{i}$, it is assumed that $E(\omega)=1$ and $\operatorname{Var}(\omega)>\operatorname{Var}(\eta)$.

An agent's maximization problem has the form:

$$
\begin{gathered}
\max u^{i}(x) \\
\text { subject to } p \cdot x \leq p \cdot \omega^{i} \text { and } x \in<Y>.
\end{gathered}
$$

The definition of an equilibrium of the asset market is standard:

\section{Definition 1}

An equilibrium of the CAPM-economy is an allocation $x^{*, i} \in\langle Y>$ for every $i \in I$ and a price $p \in<Y>$, such that:

1. $x^{*, i}$ maximizes (2.1) for all $i \in I$

2. $\sum_{I} x^{*, i}=\omega$

Note that although in general all agents are allowed not to exhaust their budget, in equilibrium they will have to do so, because market clearing requires demand to be equal to supply. 
Existence of equilibria has been proved in the CAPM with a riskless asset under assumptions weaker than those we stated above e.g. by Nielsen (1990), Allingham (1991), Dana (1999) and Hara (1998). For the case without a riskless asset under some additional assumptions Nielsen (1990), Allingham (1991) and Laitenberger (1998) give existence results. In any case, if there is an equilibrium, the next proposition shows that it features a lot of powerful properties. Based on these properties we follow Dana (1999) and transform the general CAPM into a simple equivalent two commodity equilibrium model. We have taken this part of our paper from Laitenberger (1998). To the best of our knowledge the transformation from $L^{2}$ to $\mathbb{R}^{2}$ has so far only been given for the case of a riskless asset ${ }^{1}$.

\section{Proposition 1}

In an equilibrium, the following relations hold: for every agent $i$, there exist $\phi^{i} \in \mathbb{R}, \psi^{i} \in \mathbb{R}_{+}$ such that

$$
x^{*, i}=\phi^{i} \eta+\psi^{i} \omega
$$

and $\phi_{0}, \psi_{0} \in \mathbb{R}$ such that:

$$
p=\phi_{0} \eta+\psi_{0} \omega
$$

Moreover in equilibrium, it must be $p \cdot \omega<p \cdot \eta$.

Proof. ${ }^{2}$ 1. In equilibrium the agents consume their whole budget.

This must be so, because in equilibrium markets clear and in the aggregate

$$
\sum_{i} p \cdot x^{*, i}=\sum_{i} p \cdot \omega^{i}
$$

If any agent had $p \cdot x^{*, i}<p \cdot \omega^{i}$ and all other agents respect their budget constraint $p \cdot x^{*, j} \leq$ $p \cdot \omega^{j}$, then (2.5) could not hold.

2. Let $x^{i}$ be the equilibrium choice of agent $i$ at the price $p$. Decompose $x^{i}=y^{i}+z^{i}$, where $y^{i} \in\left\langle\eta, p>\right.$ and $z^{i}$ is orthogonal to $\left\langle\eta, p>\right.$. Since $z^{i} \perp p, p \cdot y^{i}=p \cdot x^{i}$ and $y^{i}$ lies in the budget frontier of agent $i$. Since $z^{i} \perp \eta, \eta \cdot x^{i}=\eta \cdot y^{i}$, but this implies

$$
\operatorname{Cov}\left(\eta, x^{i}\right)+\mathrm{E}\left(x^{i}\right)=\operatorname{Cov}\left(\eta, y^{i}\right)+\mathrm{E}\left(y^{i}\right)
$$

and with Lemma 2 part 2. this implies $\mathrm{E}\left(x^{i}\right)=\mathrm{E}\left(y^{i}\right)$.

Since $y^{i}$ and $z^{i}$ are orthogonal, $E\left(y^{i} z^{i}\right)=0$, and with $E\left(z^{i}\right)=0$, it immediately follows that $\operatorname{Cov}\left(y^{i}, z^{i}\right)=0$, and this implies

$$
\operatorname{Var}\left(x^{i}\right)=\operatorname{Var}\left(y^{i}\right)+\operatorname{Var}\left(z^{i}\right) \geq \operatorname{Var}\left(y^{i}\right) .
$$

Since $x^{i}$ is most preferred, it must be

$$
0=\operatorname{Var}\left(z^{i}\right)=\mathrm{E}\left(\left(z^{i}\right)^{2}\right)-\left(\mathrm{E}\left(z^{i}\right)\right)^{2}=\mathrm{E}\left(\left(z^{i}\right)^{2}\right),
$$

\footnotetext{
${ }^{1}$ See however LeRoy $\&$ Werner (2001) for a similar transformation in a more restrictive setting.

${ }^{2}$ For the special case of utilities derived from quadratic von Neumann-Morgenstern utility of wealth functions, a similar proof has been given by Geanakoplos $\&$ Shubik (1990).
} 
This in turn implies $z^{i}=0$.

Thus for all agents, there are real numbers $\lambda^{i}, \xi^{i}$, such that

$$
x^{i}=\lambda^{i} \eta+\xi^{i} p .
$$

3. In equilibrium $\sum_{i} x^{i}=\sum_{i} \lambda^{i} \eta+\sum_{i} \xi^{i} p=\omega$. Thus

$$
p=\frac{1}{\sum_{i} \xi^{i}} \omega-\frac{\sum_{i} \lambda^{i}}{\sum_{i} \xi^{i}} \eta
$$

if $\sum_{i} \xi^{i} \neq 0$. The inverse, $\sum_{i} \xi^{i}=0$, is excluded, since it was assumed that $\omega$ and $\eta$ are not collinear.

Writing $p$ in the above form, one concludes:

$$
x^{i}=\left(\lambda^{i}-\frac{\xi^{i}}{\sum_{i} \xi_{i}} \sum_{i} \lambda^{i}\right) \eta+\frac{\xi^{i}}{\sum_{i} \xi^{i}} \omega .
$$

4. Assume $p \cdot \omega \geq p \cdot \eta$. Let $x^{i}=\phi^{i} \eta+\psi^{i} \omega$ be the choice of agent $i$, and assume $\psi^{i}>0$. Take $y=\left(\phi^{i}+\psi^{i}\right) \eta$. Clearly $\mathrm{E}(y)=\mathrm{E}\left(x^{i}\right)$ and $\operatorname{Var}(y)<\operatorname{Var}\left(x^{i}\right)$. Furthermore $p \cdot y=(p \cdot \eta)\left(\phi^{i}+\psi^{i}\right) \leq \phi^{i}(p \cdot \eta)+\psi^{i}(p \cdot \omega)=p \cdot x^{i}$. Thus $x^{i}$ cannot be maximizing agent $i$ 's utility function. Therefore $\psi^{i} \leq 0$ for all $i$. But then $\sum_{i} \psi^{i} \leq 0$, which is impossible, because at equilibrium $\sum_{i} x^{i}=\omega$ and therefore $\sum_{i} \psi^{i}=1$. Thus it must be: $p \cdot \omega<p \cdot \eta$.

5. Assume $x^{i}=\phi^{i} \eta+\psi^{i} \omega$ with $\psi^{i}<0$. Then $y=\left(\phi^{i}+\psi^{i}\right) \eta$ has $\mathrm{E}(y)=\mathrm{E}\left(x^{i}\right)$ and $\operatorname{Var}(y)<\operatorname{Var}\left(x^{i}\right)$ and since $p \cdot \omega<p \cdot \eta, p \cdot y=(p \cdot \eta)\left(\phi^{i}-\left|\psi^{i}\right|\right)<\phi^{i}(p \cdot \eta)-\left|\psi^{i}\right|(p \cdot \omega)=p \cdot x^{i}$. Therefore $x^{i}$ cannot be agent $i$ 's choice, and thus $\psi^{i} \geq 0$ for all $i \in I$.

Given the insights of the last proposition, information about the equilibrium can be gained by solving a simplified problem, namely one in which investors do not choose their portfolio among all securities in $Y$, but only among $\eta$ and $\omega$. The investors' new problem then has the following shape:

$$
\begin{gathered}
\max u^{i}(\phi \eta+\psi \omega) \\
\text { subject to } p \cdot \eta \phi+p \cdot \omega \psi \leq p \cdot \eta \bar{\phi}^{i}+p \cdot \omega \bar{\psi}^{i},
\end{gathered}
$$

where $\bar{\omega}^{i}=\eta \bar{\phi}^{i}+\omega \bar{\psi}^{i}$ is the orthogonal projection of $\omega^{i}$ onto $<\eta, \omega>$. $\bar{\phi}^{i}$ and $\bar{\psi}^{i}$ can be computed as:

$$
\bar{\psi}^{i}=\frac{\operatorname{Cov}\left(\eta, \omega^{i}\right)-\operatorname{Cov}\left(\omega, \omega^{i}\right)}{\operatorname{Var}(\eta)-\operatorname{Var}(\omega)}, \quad \bar{\phi}^{i}=\mathrm{E}\left(\omega^{i}\right)-\bar{\psi}^{i}
$$

It will turn out that it is more practical to use instead of the base elements $\eta$ and $\omega$, the equivalent base consisting of $\eta$ and $\omega-\eta$. The use of $(\omega-\eta)$ has several advantages. First, for the general perception of the facts, it is very intuitive to have one base element closely related to the entity 'standard deviation'. Secondly, since some computing will have to be done, it is 
obviously very helpful to have $\mathrm{E}(\omega-\eta)=\operatorname{Cov}(\eta, \omega-\eta)=0$. Finally, the main reason for the use of $(\omega-\eta)$ as a base element is that due to the last line in proposition 1 in equilibrium its price has to be negative, so that we can use the price normalization $p \cdot(\omega-\eta)=-1$.

From now on we use the following notation. The space of allowed asset-trades is spanned by $\eta$ and $\hat{\sigma}=\frac{1}{\|\omega-\eta\|^{2}}(\omega-\eta)$. Given the assumptions on $\omega$, one has:

$$
\mathrm{E}(\hat{\sigma})=0, \quad \operatorname{Var}(\hat{\sigma})=1 .
$$

For a consumption vector $x=\alpha \eta+\beta \hat{\sigma}$, the following holds:

$$
\mathrm{E}(x)=\alpha, \quad \operatorname{Var}(x)=\operatorname{Var}(\eta) \alpha^{2}+\beta^{2} .
$$

The endowment of agent $i$ is given as

$$
\bar{\omega}^{i}=\bar{\alpha}^{i} \eta+\bar{\beta}^{i} \hat{\sigma}
$$

with $\bar{\alpha}^{i}=\bar{\phi}^{i}+\bar{\psi}^{i}$ and $\bar{\beta}^{i}=\|\omega-\eta\|^{2} \bar{\psi}^{i}$.

An equilibrium in these new notations is then defined as:

Definition 2 An equilibrium of the $\mu-\sigma$-economy is an allocation $\alpha^{*, i}, \beta^{*, i} \in \mathbb{R}^{2}$ for every $i \in I$ and a price $r^{*} \in \mathbb{R}$, such that:

1. $\alpha^{*, i}, \beta^{*, i}$ maximizes

$$
\begin{gathered}
v^{i}\left(\alpha, \sqrt{\operatorname{Var}(\eta) \alpha^{2}+\beta^{2}}\right) \\
\text { subject to } \quad r^{*} \alpha-\beta \leq r^{\bar{*}} \alpha^{i}-\bar{\beta}^{i},
\end{gathered}
$$

2. $\sum_{I} \alpha^{*, i}=1, \quad \sum_{I} \beta^{*, i}=\|\omega-\eta\|^{2}$.

This definition concludes the presentation of the model.

\section{Uniqueness of EQUilibria in the CAPM With A RISKLESS ASSET}

In this section we assume that there is a riskless asset, i.e. $\mathbf{1} \in\langle Y>$. In this case $\eta=\mathbf{1}$ and the price of $\eta$ has to be positive as can be shown by a simple no-arbitrage argument, see Bottazzi et al. (1998). We can then use the price normalization $p \cdot \eta=1$. Now the decision problem derived in the previous section can be simplified to

$$
\max _{(\mu, \sigma)} v^{i}(\mu, \sigma)
$$




$$
\text { s.t. } \mu-q \sigma \leq \bar{\mu}^{i}-q \bar{\sigma}^{i}
$$

where $\bar{\mu}^{i}=E\left(\omega^{i}\right)$ and $\bar{\sigma}^{i}=\sqrt{\operatorname{Cov}\left(\omega^{i}, \omega\right)}$. The discussion of the various conditions for uniqueness will be in terms of the slope of the indifference curves in the $(\mu, \sigma)$-diagram,

$$
S^{i}(\mu, \sigma):=-\frac{\partial_{\sigma} v^{i}(\mu, \sigma)}{\partial_{\mu} v^{i}(\mu, \sigma)} .
$$

This slope is a measure of the investor's risk aversion, as Nielsen (1988) and Lajari and Nielsen (1994) have shown: Define a simple portfolio problem as a decision problem where an investor maximizes utility over portfolios formed by one riskless and one risky asset. Lajari and Nielsen (1994) then show that non-increasing risk aversion is equivalent to the property that in every simple decision problem the demand of the risky asset is non-increasing in income. Moreover, as we will show, how $S^{i}(\mu, \sigma)$ changes with $\mu$ is the key determinant for the monotonicity of the agent's optimal choice $\sigma^{i}$ as a function of $q$. The following terminology is quite useful.

\section{Definition 3}

A mean-variance utility function exhibits non increasing (non decreasing) risk aversion if for all $\sigma \geq 0$ the slope of its indifference curves are non increasing (non decreasing) functions in mean. It exhibits constant absolute risk aversion if this slope is constant.

The next Lemma shows how the slope of an agent's risk aversion $\partial_{\mu} S^{i}\left(\mu^{i}, \sigma^{i}\right)$ determines the slope of his demand for risk $\partial_{q} \sigma(q)$.

Lemma 2(individual monotonicity)

Let $\left(\mu^{i}(q), \sigma^{i}(q)\right) \in \operatorname{argmax} v^{i}(\mu, \sigma)$ s.t. $\mu-q \sigma \leq \bar{\mu}^{i}-q \bar{\sigma}^{i}$. Then

(a) $\partial_{q} \sigma^{i}(q) \gtreqless 0$ iff $\partial_{\mu} S^{i}\left(\mu^{i}(q), \sigma^{i}(q)\right)\left(\sigma^{i}(q)-\bar{\sigma}^{i}\right) \leq 1$ and

(b) $\partial_{q} \sigma^{i}(q)>0$ if $\partial_{\mu} S^{i}\left(\mu^{i}(q), \sigma^{i}(q)\right)\left(\mu^{i}(q)-\bar{\mu}^{i}(q)\right) \leq 0$.

\section{Proof}

By assumption higher mean is preferred, hence the budget restriction holds with equality. Therefore, consider

$$
\max _{\sigma \geq 0} v^{i}\left(\bar{\mu}^{i}-q \bar{\sigma}^{i}+q \sigma, \sigma\right) .
$$

The first order condition for an optimal solution is

$$
\partial_{\mu} v^{i}\left(\bar{\mu}^{i}-q \bar{\sigma}^{i}+q \sigma, \sigma\right) q+\partial_{\sigma} v^{i}\left(\bar{\mu}^{i}-q \bar{\sigma}^{i}+q \sigma, \sigma\right)=0 .
$$

Yielding 


$$
\frac{d \sigma}{d q}=\frac{\left[\left(\partial_{\mu} v^{i}\right)+\left(\partial_{\mu}^{2} v^{i}\right) q\left(\sigma-\bar{\sigma}^{i}\right)+\left(\partial_{\mu} \partial_{\sigma} v^{i}\right)\left(\sigma-\bar{\sigma}^{i}\right)\right]}{-\left[\left(\left(\partial_{\sigma} \partial_{\mu} v^{i}\right)+\partial_{\mu}^{2} v^{i} q\right) q+\left(\partial_{\mu} \partial_{\sigma} v^{i}\right) q+\left(\partial_{\sigma}^{2} v^{i}\right)\right]}
$$

Note that by strict quasi-concavity of $v^{i}$ the denominator in this expression is strictly positive. Furthermore, since $\left(\partial_{\mu} v^{i}\right)>0$ it is obtained that

$$
\frac{d \sigma}{d q}>0 \text { iff } 1+\frac{\left[\left(\partial_{\mu}^{2} v^{i}\right) q+\left(\partial_{\mu} \partial_{\sigma} v^{i}\right)\right]\left(\sigma-\bar{\sigma}^{i}\right)}{\left(\partial_{\mu} v^{i}\right)}>0 .
$$

Substitution of $q=-\frac{\partial_{\sigma} v^{i}}{\partial_{\mu} v^{i}}$ from the (FOC) and using the identity $\partial_{\mu} S^{i}=-\frac{\left[\left(\partial_{\mu} \partial_{\sigma} v^{i}\right)\left(\partial_{\mu} v^{i}\right)-\left(\partial_{\mu}^{2} v^{i}\right)\left(\partial_{\sigma} v^{i}\right)\right]}{\left(\partial_{\mu} v^{i}\right)^{2}}$ proves our claim (a).

To see the second claim (b), substitute $\left(\sigma-\bar{\sigma}^{i}\right)=\frac{\left(\mu-\bar{\mu}^{i}\right)}{q}$ from the budget equation into claim (a), recognizing that $q>0$.

¿From Lemma 3 we get the following condition for uniqueness of equilibria in the CAPM:

\section{Theorem 1}

When there is a riskless asset, CAPM equilibria are unique if every agent has on the one hand non-decreasing (on the other hand non-increasing) absolute risk aversion for mean-variance combinations with mean smaller (resp.larger) than the expected value of her endowments and variance smaller(resp. larger) than the covariance of her endowments and the market portfolio.

\section{Proof}

For each $q>0$, every agent $i=1, \ldots, I$ can be in one of the following situations:

\begin{tabular}{ll|c|c|l} 
& & $\partial_{\mu} S^{i}$ & $\partial_{q} \sigma^{i}(q)$ & result follows \\
\hline$(1)$ & $\sigma^{i}(q)<\bar{\sigma}^{i}, \mu^{i}(q)<\bar{\mu}^{i}$ & 0 & $\geq 0$ & from (a) or from (b) \\
$(2)$ & $\sigma^{i}(q)<\bar{\sigma}^{i}, \mu^{i}(q) \geq \bar{\mu}^{i}$ & $\leq 0$ & $>0$ & from (b) \\
$(3)$ & $\sigma^{i}(q) \geq \bar{\sigma}^{i}, \mu^{i}(q)<\bar{\mu}^{i}$ & $\leq 0$ & $>0$ & from (a) \\
$(4)$ & $\sigma^{i}(q) \geq \bar{\sigma}^{i}, \mu^{i}(q) \geq \bar{\mu}^{i}$ & $\leq 0$ & $>0$ & from (a) or from (b)
\end{tabular}

Thus every individual demand function is strictly monotone and therefore "market demand" $\sum_{i=1}^{I} \sigma^{i}(q)$ is strictly monotone. Hence there is at most one equilibrium. From the existence results mentioned above follows that there is at least one equilibrium. Therefore, there is a unique equilibrium.

- Figure 1 (see end of text) -

Figure 1 shows a set of indifference curves satisfying the assumptions of Theorem 1 . In the area (1), for all $\sigma$ the slope of the indifference curves are non-decreasing as a function of $\mu$. In areas (2), (3) and (4) for all $\sigma$ this slope is non-increasing in $\mu$. 
The condition used in Theorem 1 is a joint restriction on individual's resources and their preferences. The following Corollary 1 demonstrates uniqueness of equilibria as being derived from an assumption on $v^{i}$ only.

\section{Corollary 1}

CAPM equilibria are unique if all agents have constant risk aversion.

\section{Proof}

In the case of constant risk aversion, $\partial_{\mu} S^{i}=0$ for all $i=1, \ldots, I$. Hence both conditions of Lemma 1 are can be applied to obtain this result.

Corollary 1 establishes uniqueness in the CAPM for the case of constant absolute risk aversion without any distributional assumptions on the payoffs thus generalizing the well known uniqueness result for the case of exponential utility functions and normally distributed returns.

An interesting observation, which was pointed out to us by an anonymous referee of this journal, is that constant absolute risk aversion holds if and only if the mean variance utility functions $v^{i}(\mu, \sigma)$ are quasi-linear, i.e. if they can be represented as $v^{i}(\mu, \sigma)=\mu-h_{i}(\sigma)$ for some convex function $h_{i}{ }^{3}$

This observation relates the uniqueness of CAPM-equilibria in this case nicely to the results on uniqueness found in the general equilibrium literature since quasi-linearity is a well known condition for uniqueness of general equilibria. However, without a riskless asset quasi-linearity does not need to follow from constant absolute risk aversion. And indeed in the next section we will demonstrate by means of an example that without a riskless asset CAPM-equilibria need not be unique even though all agents have constant absolute risk aversion.

\section{Multiplicity of equilibria in the CAPM without a RISKLESS ASSET}

The framework in this section is the same as in section 3, except that we assume now $\mathbf{1} \notin Y$.

In the following we will demonstrate that condition given in Theorem 1 is not sufficient to guarantee a unique equilibrium in the CAPM with risky assets only. We will construct an

\footnotetext{
${ }^{3}$ The "if" part of this claim follows directly from this functional form by applying it to the definition of constant absolute risk aversion, i.e. to $\partial_{\mu} S^{i}(\mu, \sigma)=0$. To see the "only if" part note that constant absolute risk aversion implies that the mean-variance-preference ordering of any two points in $L^{2}$ or equivalently in the mean-variance diagram remains unchanged by addition of any scalar multiple of the riskless asset to both points. Hence for any two points $\left(\mu_{1}, \sigma_{1}\right),\left(\mu_{2}, \sigma_{2}\right)$ such that $v^{i}\left(\mu_{1}, \sigma_{1}\right)=v^{i}\left(\mu_{2}, \sigma_{2}\right)$ we get that $v^{i}\left(0, \sigma_{1}\right)=v^{i}\left(\mu_{2}-\mu_{1}, \sigma_{2}\right)$. That is to say since the LHS is independent from $\mu$ the RHS must also be independent from $\mu$ thus there must exist some convex function $h_{i}$ such that $v^{i}(\mu, \sigma)=\mu-h_{i}(\sigma)$.
} 
economy with two assets and two constantly risk averse investors that exhibits (at least) two equilibria.

To make things easier we assume $\operatorname{Var}(\eta)=1$. Recall from the transformation outlined in section 2 that any investor $i$ solves the maximization problem

$$
\max v^{i}\left(\alpha, \sqrt{(\alpha)^{2}+(\beta)^{2}}\right) \quad \text { s.t. } \quad \alpha-q \beta \leq \bar{\alpha}^{i}-q \bar{\beta}^{i} .
$$

This formulation already reveals the intuition of our example. Although the utility function in $\mu$ and $\sigma$ is quasi-linear, the transformed problem in the $(\alpha, \beta)$ space will not be quasi-linear. Hence, multiple solutions might exist and it remains to show the details. To this end we choose the endowments of the investors as

$$
\left(\overline{\alpha^{1}}, \bar{\beta}^{1}\right)=(0.546,0.975), \quad\left(\bar{\alpha}^{2}, \bar{\beta}^{2}\right)=(0.454,0.025) .
$$

Notice that both endowments add to one which will be important later.

The utility functions exhibit constant absolute risk aversion, hence the utility $v^{i}$ are of the functional form

$$
v^{i}(\mu, \sigma)=\mu-h_{i}(\sigma)
$$

where $h_{i}$ is a strictly convex and strictly monotone function. For our example it will be enough to show that the first derivative is positive and monotone at two points since then $h_{i}$ can easily be extended on $\mathbb{R}_{+}$. In particular we assume that

$$
\begin{array}{cl}
h_{1}^{\prime}(0.17)=1.2 & h_{1}^{\prime}(0.172)=1.21 \\
h_{2}^{\prime}(1.152)=0.3718 & h_{2}^{\prime}(1.17)=0.6667
\end{array}
$$

To derive the equilibria consider the first order conditions according to (4.7), $i=1,2$

$$
\begin{gathered}
1-2 \alpha h_{i}^{\prime}\left(\alpha^{2}+\beta^{2}\right)-\lambda q=0 \\
-2 \beta h_{i}^{\prime}\left(\alpha^{2}+\beta^{2}\right)+\lambda q=0 .
\end{gathered}
$$

The budget constraint must be binding at equilbrium if $\lambda_{i}>0$ which is implied by $1-$ $2 \alpha h_{i}^{\prime}\left(\alpha^{2}+\beta^{2}\right)>0$. The first order conditions can therefore be simplified to

$$
\frac{1-2 \alpha h_{i}^{\prime}\left(\alpha^{2}+\beta^{2}\right)}{2 \beta h_{i}^{\prime}\left(\alpha^{2}+\beta^{2}\right)}=q>0
$$

which will ensure non-satiation at equilibrium. If markets clear and since endowments add to one this condition can be written using the optimal portfolio $\left(\alpha^{*}, \beta^{*}\right)$ of investor one

$$
\frac{1-2 \alpha^{*} h_{1}^{\prime}\left(\alpha^{* 2}+\beta^{* 2}\right)}{2 \beta^{*} h_{1}^{\prime}\left(\alpha^{* 2}+\beta^{* 2}\right)}=\frac{1-2\left(1-\alpha^{*}\right) h_{2}^{\prime}\left(\left(1-\alpha^{*}\right)^{2}+\left(1-\beta^{*}\right)^{2}\right)}{2\left(1-\beta^{*}\right) h_{2}^{\prime}\left(\left(1-\alpha^{*}\right)^{2}+\left(1-\beta^{*}\right)^{2}\right)}=q^{*}>0 .
$$


Our example will be complete if we determine the optimal portfolio $\left(\alpha^{*}, \beta^{*}\right)$ of investor one and show that $\left(1-\alpha^{*}, 1-\beta^{*}\right)$ is optimal for investor two or, which is the same, satisfies (4.9). The following portfolios and prices will do

$$
\begin{array}{ccc}
\left(\alpha_{(1)}^{*}, \beta_{(1)}^{*}\right)=(0.4,0.1), & \left(1-\alpha_{(1)}^{*}, 1-\beta_{(1)}^{*}\right)=(0.6,0.9), & q_{(1)}^{*}=0.16667 \\
\left(\alpha_{(2)}^{*}, \beta_{(2)}^{*}\right)=(0.11,0.6), & \left(1-\alpha_{(2)}^{*}, 1-\beta_{(2)}^{*}\right)=(0.89,0.4), & q_{(2)}^{*}=0.75806
\end{array}
$$

Using our assumption on the first derivative of $h_{1}$ and $h_{2}$ it is now straightforward to verify that both equilibria satisfy our condition (4.9). Moreover at these equilibria all budget constraints are indeed satisfied with equality. We therefore have constructed a CAPM with at least two equilibria.

Finally note that if the functions $h_{i}(\sigma)$ were of the functional form $c_{i} \sigma^{2}$ for some positive constant $c_{i}$, then our construction of multiple equilibria does not work because the single parameter $c_{i}$ is not sufficient to determine two values of $h_{i}^{\prime}$. And indeed in this case, as Allingham (1991) has demonstrated, equilibria are unique even when there is no riskless asset. 


\section{REFERENCES}

Allingham, M. (1991). Existence theorems in the CAPM. Econometrica, 59, 1169-1174.

Arrow, K.J. and F. Hahn (1971). General Competitive Analysis. San Francisco: Holden Day.

Bottazzi, J.-M., T. Hens, and A. Löffler (1998). Market demand functions in the CAPM. Journal of Economic Theory, 79, 192-206.

Dalal, A.J. and B.G. Arshanapalli (1993). Estimating the Demand for Risky Assets via the Indirect Expected Utility Function, Journal of Risk and Uncertainty, 6, 277-288.

Dana, R.A. (1999). Existence, Uniqueness and Determinacy of Equilibrium in CAPM with a riskless asset, Journal of Mathematical Economics, (32),(2),167-75.

Duffie, D. (1988). Security Markets. San Diego: Academic Press, Inc.

Geanakoplos, J. and M. Shubik (1990). The Capital Asset Pricing Model as a General Equilibrium with Incomplete Markets Model. The Geneva Papers on Risk and Insurance Theory, 15, 55-72.

Hara,C. (1998). Prices of the Market Portfolio in the CAPM with Incomplete Markets, mimeo Cambridge University.

Karatzas, I., J.P. Lehoczky, and S.E. Shreve (1990). Existence and Uniqueness of MultiAgent Equilibrium in a Stochastic, Dynamic Consumption/Investment Model. Mathematics of Operations Research, 15, 80-128.

Laitenberger, J. (1998). Demand Theory in Models of Financial Markets. Dissertation, University of Bonn.

Lajeri, F. and L.T. Nielsen (1994, April). Risk Aversion and Prudence: The Case of MeanVariance Preferences. INSEAD.

LeRoy, S.E. and J. Werner (2001). Principles of Financial Economics. mimeo University of Minnessotta, Minneapolis.

Levy, H. (1994). Absolute and Relative Risk Aversion: An Experimental Study Journal of Risk and Uncertainty, 8, 289-307.

Lintner, J. (1965). The Valuation of Risky Assets and the Selection of Risky Investments in Stock Portfolios and Capital Budgets. Review of Economics and Statistics, 47, 13-37. 
Löffler, A. (2000). A $\mu-\sigma-$ Risk Aversion Paradox and Wealth Dependent Utility. to appear in Journal of Risk and Uncertainty. URL: http://www.wiwiss.fuberlin.de/w3/w3krusch/pub/drra.htm

Mas-Colell, A. (1985). The Theory of General Equilibrium. A Differentiable Approach. Econometric Society Monographs: Cambridge University Press.

Mas-Colell, A. and M.D. Whinston and J.R. Green (1995). Microeconomic Theory. Oxford: Oxford University Press.

Merton, R.C. (1973). An Intertemporal Capital Asset Pricing Model. Econometrica, 41, $867-888$.

Mossin, J. (1966). Equilibrium in a Capital Asset Market. Econometrica, 34, 768-783.

Nielsen, L.T. (1988). Uniqueness of Equilibrium in the Classical Capital Asset Pricing Model. Journal of Financial and Quantitative Analysis, 23, 329-336.

Nielsen, L.T. (1990). Existence of Equilibrium in CAPM. Journal of Economic Theory, 52, $223-231$.

Sharpe, W. (1964). Capital Asset Prices: A Theory of Market Equilibrium Under Conditions of Risk. Journal of Finance, 19, 425-442. 


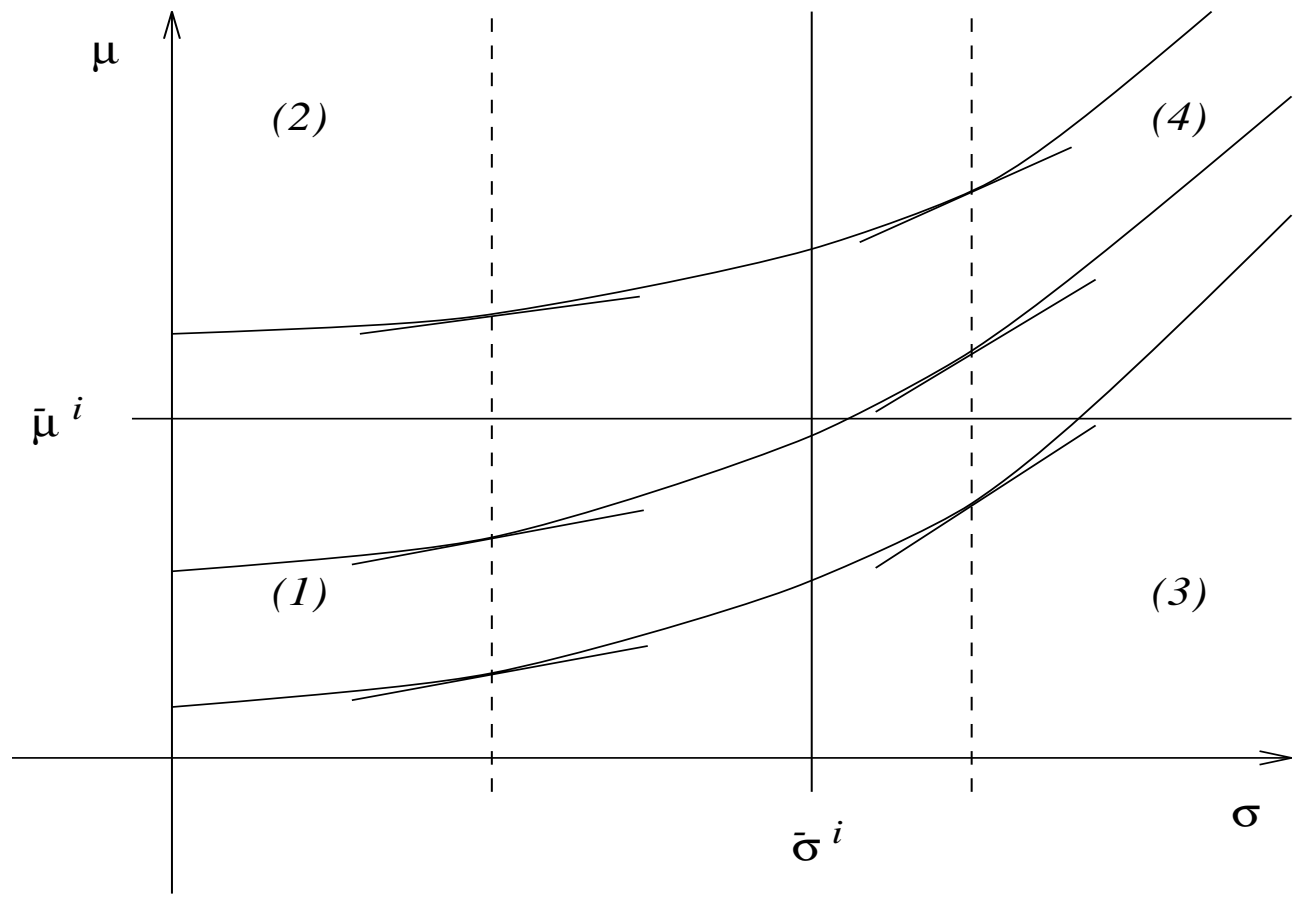

- Figure 1 - 


\section{Working Papers of the Institute for Empirical Research in Economics}

No.

1. Rudolf Winter-Ebmer and Josef Zweimüller: Firm Size Wage Differentials in Switzerland: Evidence from Job Changers, February 1999

2. Bruno S. Frey and Marcel Kucher: History as Reflected in Capital Markets: The Case of World War II, February 1999

3. Josef Falkinger, Ernst Fehr, Simon Gächter and Rudolf Winter-Ebmer: A Simple Mechanism for the Efficient Provision of Public Goods - Experimental Evidence, February 1999

4. Ernst Fehr and Klaus M. Schmidt: A Theory of Fairness, Competition and Cooperation, April 1999

5. Markus Knell: Social Comparisons, Inequality, and Growth, April 1999

6. Armin Falk and Urs Fischbacher: A Theory of Reciprocity, April 1999

7. Bruno S. Frey and Lorenz Goette: Does Pay Motivate Volunteers?, May 1999

8. Rudolf Winter-Ebmer and Josef Zweimüller: Intra-firm Wage Dispersion and Firm Performance, May 1999

9. Josef Zweimüller: Schumpeterian Entrepreneurs Meet Engel's Law: The Impact of Inequality on InnovationDriven Growth, May 1999

10. Ernst Fehr and Simon Gächter: Cooperation and Punishment in Public Goods Experiments, June 1999

11. Rudolf Winter-Ebmer and Josef Zweimüller: Do Immigrants Displace Young Native Workers: The Austrian Experience, June 1999

12. Ernst Fehr and Jean-Robert Tyran: Does Money Illusion Matter?, June 1999

13. Stefan Felder and Reto Schleiniger: Environmental Tax Reform: Efficiency and Political Feasibility, July 1999

14. Bruno S. Frey: Art Fakes - What Fakes?, An Economic View, July 1999

15. Bruno S. Frey and Alois Stutzer: Happiness, Economy and Institutions, July 1999

16. Urs Fischbacher, Simon Gächter and Ernst Fehr: Are People Conditionally Cooperative? Evidence from a Public Goods Experiment, July 2000

17. Armin Falk, Ernst Fehr and Urs Fischbacher: On the Nature of Fair Behavior, August 1999

18. Vital Anderhub, Simon Gächter and Manfred Königstein: Efficient Contracting and Fair Play in a Simple Principal-Agent Experiment, August 1999

19. Simon Gächter and Armin Falk: Reputation or Reciprocity?, September 1999

20. Ernst Fehr and Klaus M. Schmidt: Fairness, Incentives, and Contractual Choices, September 1999

21. Urs Fischbacher: $z$-Tree - Experimenter's Manual, September 1999

22. Bruno S. Frey and Alois Stutzer: Maximising Happiness?, October 1999

23. Alois Stutzer: Demokratieindizes für die Kantone der Schweiz, October 1999

24. Bruno S. Frey: Was bewirkt die Volkswirtschaftslehre?, October 1999

25. Bruno S. Frey, Marcel Kucher and Alois Stutzer: Outcome, Process \& Power in Direct Democracy, November 1999

26. Bruno S. Frey and Reto Jegen: Motivation Crowding Theory: A Survey of Empirical Evidence, November 1999

27. Margit Osterloh and Bruno S. Frey: Motivation, Knowledge Transfer, and Organizational Forms, November 1999

28. Bruno S. Frey and Marcel Kucher: Managerial Power and Compensation, December 1999

29. Reto Schleiniger: Ecological Tax Reform with Exemptions for the Export Sector in a two Sector two Factor Model, December 1999

30. Jens-Ulrich Peter and Klaus Reiner Schenk-Hoppé: Business Cycle Phenomena in Overlapping Generations Economies with Stochastic Production, December 1999

31. Josef Zweimüller: Inequality, Redistribution, and Economic Growth, January 2000

32. Marc Oliver Bettzüge and Thorsten Hens: Financial Innovation, Communication and the Theory of the Firm, January 2000

33. Klaus Reiner Schenk-Hoppé: Is there a Golden Rule for the Stochastic Solow Growth Model? January 2000

34. Ernst Fehr and Simon Gächter: Do Incentive Contracts Crowd out Voluntary Cooperation? February 2000

35. Marc Oliver Bettzüge and Thorsten Hens: An Evolutionary Approach to Financial Innovation, July 2000

36. Bruno S. Frey: Does Economics Have an Effect? Towards an Economics of Economics, February 2000

37. Josef Zweimüller and Rudolf Winter-Ebmer: Firm-Specific Training: Consequences for Job-Mobility, March 2000

The Working Papers of the Institute for Empirical Research in Economics can be downloaded in PDF-format from http://www.unizh.ch/iew/wp/ 


\section{Working Papers of the Institute for Empirical Research in Economics}

No.

38. Martin Brown, Armin Falk and Ernst Fehr: Contract Inforcement and the Evolution of Longrun Relations, March 2000

39. Thorsten Hens, Jörg Laitenberger and Andreas Löffler: On Uniqueness of Equilibria in the CAPM, July 2000

40. Ernst Fehr and Simon Gächter: Fairness and Retaliation: The Economics of Reciprocity, March 2000

41. Rafael Lalive, Jan C. van Ours and Josef Zweimüller: The Impact of Active Labor Market Programs and Benefit Entitlement Rules on the Duration of Unemployment, March 2000

42. Reto Schleiniger: Consumption Taxes and International Competitiveness in a Keynesian World, April 2000

43. Ernst Fehr and Peter K. Zych: Intertemporal Choice under Habit Formation, May 2000

44. Ernst Fehr and Lorenz Goette: Robustness and Real Consequences of Nominal Wage Rigidity, May 2000

45. Ernst Fehr and Jean-Robert Tyran: Does Money Illusion Matter? REVISED VERSION, May 2000

46. Klaus Reiner Schenk-Hoppé: Sample-Path Stability of Non-Stationary Dynamic Economic Systems, Juni 2000

47. Bruno S. Frey: A Utopia? Government without Territorial Monopoly, June 2000

48. Bruno S. Frey: The Rise and Fall of Festivals, June 2000

49. Bruno S. Frey and Reto Jegen: Motivation Crowding Theory: A Survey of Empirical Evidence, REVISED VERSION, June 2000

50. Albrecht Ritschl and Ulrich Woitek: Did Monetary Forces Cause the Great Depression? A Bayesian VAR Analysis for the U.S. Economy, July 2000

51. Alois Stutzer and Rafael Lalive: The Role of Social Work Norms in Job Searching and Subjective Well-Being, July 2000

52. Iris Bohnet, Bruno S. Frey and Steffen Huck: More Order with Less Law: On Contract Enforcement, Trust, and Crowding, July 2000

53. Armin Falk and Markus Knell: Choosing the Joneses On the Endogeneity of Reference Groups, July 2000

The Working Papers of the Institute for Empirical Research in Economics can be downloaded in PDF-format from http://www.unizh.ch/iew/wp/

Institute for Empirical Research in Economics, Blümlisalpstr. 10, 8006 Zürich, Switzerland

Phone: 004116343705 Fax:0041 16344907 E-mail: bibiewzh@iew.unizh.ch 